\title{
HDL and Lifestyle Interventions
}

\author{
Joan Carles Escolà-Gil, Josep Julve, Bruce A. Griffin, Dilys Freeman, \\ and Francisco Blanco-Vaca
}

\section{Contents}

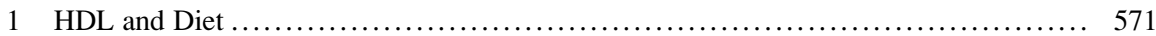

1.1 Effects of Substituting Dietary Saturated Fatty Acids ..................... 571

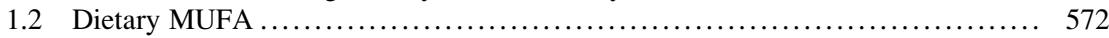

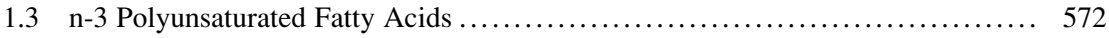

1.4 Carbohydrate and Extrinsic Sugars ................................. 573

1.5 Effects of Dietary Fatty Acids and Cholesterol on HDL Function ............. 573

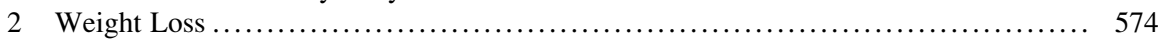

2.1 Impact of Adiposity on HDL Concentration and Function .................. 574

2.2 Effect of Weight-Loss Therapies on HDL Concentration and Function .......... 575

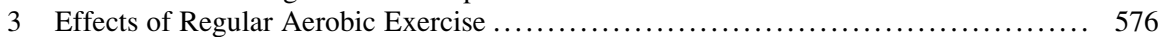

3.1 Effects of Exercise on HDL ......................................... 576

3.2 Effects of Exercise on Prevention and Treatment of Cardiometabolic Risk ...... 577

$4 \quad$ Smoking Cessation ........................................................ 578

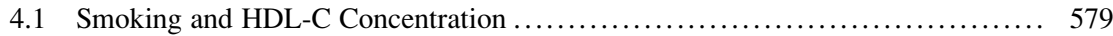

4.2 Potential Mechanisms for the Smoking-Related Reduction in HDL-C ........... 579

4.3 Smoking Cessation Intervention to Increase Plasma HDL Concentration ........ 581

J.C. Escolà-Gil • J. Julve • F. Blanco-Vaca $(\square)$

Institut d'Investigació Biomèdica (IIB) Sant Pau, Barcelona, Spain

CIBER de Diabetes y Enfermedades Metabólicas Asociadas (CIBERDEM),

Barcelona, Spain

Departament de Bioquímica i Biologia Molecular, Universitat Autònoma

de Barcelona, Barcelona, Spain

e-mail: fblancova@santpau.cat

B.A. Griffin

Department of Nutritional Sciences, University of Surrey, Surrey, UK

D. Freeman

Institute of Cardiovascular and Medical Sciences, University of Glasgow, Glasgow, UK

(C) The Author(s) 2015

A. von Eckardstein, D. Kardassis (eds.), High Density Lipoproteins, Handbook of

Experimental Pharmacology 224, DOI 10.1007/978-3-319-09665-0_18 
5 Effects of Alcohol on HDL and Cardiovascular Risk .......................... 582

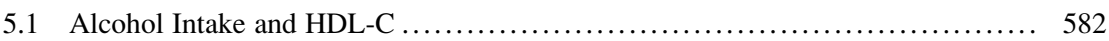

5.2 Effects of Alcohol on HDL Atheroprotective Functions .................... 583

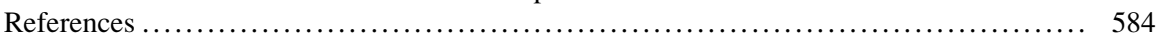

\section{Abstract}

The main lifestyle interventions to modify serum HDL cholesterol include physical exercise, weight loss with either caloric restriction or specific dietary approaches, and smoking cessation. Moderate alcohol consumption can be permitted in some cases. However, as these interventions exert multiple effects, it is often difficult to discern which is responsible for improvement in HDL outcomes. It is particularly noteworthy that recent data questions the use of HDL cholesterol as a risk factor and therapeutic target since randomised interventions and Mendelian randomisation studies failed to provide evidence for such an approach. Therefore, these current data should be considered when reading and interpreting this review. Further studies are needed to document the effect of lifestyle changes on HDL structure-function and health.

\section{Keywords}

Alcohol $\bullet$ Exercise $\bullet \mathrm{HDL} \cdot$ Fat $\bullet$ Smoking $\bullet$ Weight

\section{Abbreviations}

$\begin{array}{ll}\text { ABC } & \text { Adenosine triphosphate-binding cassette transporter } \\ \text { Apo } & \text { Apolipoprotein } \\ \text { CVD } & \text { Cardiovascular disease } \\ \text { CETP } & \text { Cholesteryl ester transfer protein } \\ \text { HL } & \text { Hepatic lipase } \\ \text { HDL-C } & \text { High-density lipoprotein cholesterol } \\ \text { LCAT } & \text { Lecithin-cholesterol acyltransferase } \\ \text { LDL-C } & \text { Low-density lipoprotein cholesterol } \\ \text { LPL } & \text { Lipoprotein lipase } \\ \text { Lp-PLA2 } & \text { Lipoprotein-associated phospholipase A2 } \\ \text { MUFA } & \text { Monounsaturated fatty acids } \\ \text { PLTP } & \text { Phospholipid transfer protein } \\ \text { PON1 } & \text { Paraoxonase 1 } \\ \text { PUFA } & \text { Polyunsaturated fatty acids } \\ \text { RCT } & \text { Reverse cholesterol transport } \\ \text { SFA } & \text { Saturated fatty acids } \\ \text { SR-BI } & \text { Scavenger receptor class-BI } \\ \text { TAG } & \text { Triacylglycerol }\end{array}$




\section{$1 \quad H D L$ and Diet}

The landmark cross-cultural and migration studies of Ancel Keys in the 1950s were the first to identify associations between serum HDL cholesterol (HDL-C) and diet and lifestyle factors in free-living populations (Keys 1980a). These early studies laid the foundation for the development of the diet-heart hypothesis, by revealing links between the incidence of coronary heart disease, raised serum cholesterol and energy derived from saturated fat. They also helped to establish diet as a determinant of low HDL in obesity (Keys 1980b). It has been established that certain dietary saturated fatty acids (SFA), with a chain length of between 12 and 16 carbons, and dietary cholesterol can increase both serum low-density lipoprotein cholesterol (LDL-C) and, somewhat paradoxically with respect to cardiovascular disease (CVD) risk, HDL-C (Grundy and Denke 1990). Conversely, the replacement of SFA with either polyunsaturated (PUFA) or monounsaturated fatty acids (MUFA) has been shown to reduce serum HDL-C. Moreover, the replacement of dietary fat with carbohydrate has also been shown to produce significant reductions in serum HDL-C (Katan et al. 1997; Stanhope et al. 2013). Heightened awareness of the risk associated with dietary sugars in the early 1970s (Yudkin 1972) has resurfaced recently, in part, through escalation of obesity-related cardiometabolic risk and increased understanding of how extrinsic sugars influence HDL by adversely affecting the metabolism of triacylglycerol (TAG) (Lustig 2010). The history of diet and HDL has evolved in the era of the LDL-lowering statins, which are relatively ineffective in raising HDL-C, and leave behind what is often described as untreated 'residual risk' (Belsey et al. 2008). This situation has created a need for alternative HDL-targeted drugs and also increased awareness of the importance of diet as a modifier of HDL structure and function.

\subsection{Effects of Substituting Dietary Saturated Fatty Acids}

Serum HDL-C has been shown to be influenced by both the amount and quality of dietary fatty acids and carbohydrate. In the past, the relative effects of dietary fatty acids on HDL-C have been described in absolute terms, that is, SFA tends to raise HDL-C, whilst PUFA, trans fatty acids and carbohydrate, all tend to reduce HDL-C, with MUFA being relatively neutral (Grundy and Denke 1990). However, in reality the absolute effect of fatty acids, or any macronutrient, on HDL-C cannot be measured, as its addition or replacement may be counter-affected by whatever fatty acid or carbohydrate takes its place to maintain a feasible diet. This phenomenon of substitution limits the ability to interpret the impact of dietary macronutrients on HDL and CVD risk to 'relative', rather than 'absolute' effects. Meta-analyses of intervention studies have provided strong evidence to show that the iso-energetic replacement of SFA with PUFA, MUFA and carbohydrate decreases HDL-C, with carbohydrate exerting the greatest impact in lowering both HDL-C and the total cholesterol-HDL-C ratio (Mensink et al. 2003). In contrast, the iso-energetic replacement of carbohydrate with all dietary fatty 
acids, other than trans fatty acids, tends to raise HDL-C (Micha and Mozaffarian 2010). Estimates for the relative magnitude of change in the concentration of serum HDL-C in response to these dietary substitutions are directly proportional to the amount of energy being exchanged. An iso-energetic exchange of $5 \%$ energy from carbohydrate to SFA, MUFA and PUFA is associated with increases in HDL-C of $0.05,0.04$ and $0.03 \mathrm{mmol} / \mathrm{L}$, respectively, with trans fatty acids reducing HDL by $0.02 \mathrm{mmol} / \mathrm{L}$. In addition, individual SFA is known to exert differential effects on serum HDL-C, so that replacing $5 \%$ energy as carbohydrate with lauric, myristic, palmitic and stearic, increases HDL-C by $0.13,0.09,0.05$ and $<0.01 \mathrm{mmol} / \mathrm{L}$, respectively. These associations between dietary fatty acids and serum HDL-C are statistically robust and have been used to formulate dietary guidelines. However, because they rely heavily upon data from measures of dietary intake, as estimated from dietary recall, food frequency questionnaires or diet diaries, this can limit their value in predicting the biological effects of complex foods on HDL (Astrup et al. 2011). In other words, foods are not single nutrients, but complex mixtures of nutrients within a food matrix, all of which interact together to produce a biological effect. Because a food is rich in one particular fatty acid, it does not mean that consumption of this food will result in an effect on HDL that is typical of that fatty acid.

\subsection{Dietary MUFA}

Interest in the potential health benefits of dietary MUFA originated from the use of olive oil in the Mediterranean diet. Whilst substitution of SFA with MUFA is less effective in lowering LDL cholesterol than n-6 PUFA, there is evidence to suggest that this substitution may be more effective in preventing the decrease in HDL-C that accompanies the removal of SFA (Schwingshackl and Hoffmann 2012). This finding is supported by data to show that MUFA is relatively less effective in stimulating cholesteryl ester transfer protein (CETP), and thus the remodelling and increased clearance of HDL from serum, than either SFA or n-6 PUFA (Groener et al. 1991; Lagrost et al. 1999). This finding is in accord with data from a recent study which concluded that dietary MUFA reduced the catabolic rate of the principal apolipoprotein (apo) in HDL, apo A-I (Labonte et al. 2013).

\section{3 n-3 Polyunsaturated Fatty Acids}

The principal essential fatty acid of the $\mathrm{n}-3$ series, $\alpha$-linolenic acid (18:2) is the most abundant fatty acid on earth, but is consumed in significantly less quantity by humans than linoleic acid (18:2 n-6) (National Diet and Nutrition Survey. Department of Health 2011). When fed in physiologically relevant amounts, $\alpha$-linolenic acid has been shown to be equivalent to linoleic acid as a substitute for SFA in lowering LDL cholesterol (Harris 1997). However, even though a recent metaanalysis indicated a benefit of $\alpha$-linolenic acid intake on CVD risk (Pan et al. 2012), 
human interventions with $\alpha$-linolenic acid-enriched diets have shown variable effects on serum HDL-C (Harper et al. 2006; Goyens and Mensink 2006; Kaul et al. 2008; Griffin et al. 2006). The longer-chain derivatives of $\alpha$-linolenic acid, chiefly eicosapentaenoic and docosahexaenoic acids (EPA, DHA), which in humans are mainly obtained directly from oily fish, exert only a moderate elevating effect on HDL-C (Harris 1989). This is perhaps surprising given the potent TAG-lowering effect of these long-chain fatty acids.

\subsection{Carbohydrate and Extrinsic Sugars}

The replacement of dietary fat with carbohydrate in low-fat, high-carbohydrate diets has long been associated with a reduction in serum HDL-C that may be linked to the carbohydrate-induced increase in TAG (Katan et al. 1997). The latter is known to promote lipid exchanges between HDL- and TAG-rich lipoproteins that remodel HDL into smaller and denser particles with an increased catabolic rate and thus reduced residence time in serum. Adverse effects of carbohydrate on HDL-C in the longer term may also be mediated through increased body weight and the accumulation of body fat (Stanhope et al. 2013). Whilst the reduction in HDL-C has been attributed to diets with a high glycaemic index (Frost et al. 1999), there is now little doubt that the extrinsic sugars, sucrose and fructose make a major contribution to this effect (Lustig 2010). The findings of a recent meta-analysis which concluded that a very high intake of fructose $(>100 \mathrm{~g} / \mathrm{d})$ increases serum LDL cholesterol, but has no significant effects on HDL-C, are somewhat surprising in both respects (Zhang et al. 2013) and in contrast to the outcome of dietary interventions with beverages sweetened with fructose. One example of the latter showed marked increases in cardiometabolic risk factors, including significant reductions in serum HDL-C, relative to glucose-sweetened beverages (Stanhope et al. 2009). A vital question to be answered is whether populations are consuming amounts of extrinsic sugars which are sufficient to elicit these adverse changes in HDL in the long term. Dietary intakes in the United Kingdom (National Diet and Nutrition Survey. Department of Health 2011) indicate that the upper 2.5th percentile of the population may be approaching intakes of extrinsic sugars which have the potential to induce adverse effects on metabolism and increase body weight. The overconsumption of sweetened beverages in adolescents is of particular concern in promoting premature obesity and lowering of HDL-C, as shown in a recent Australian study (Ambrosini et al. 2013).

\subsection{Effects of Dietary Fatty Acids and Cholesterol on HDL Function}

HDL-C is a surrogate marker of HDL particle size and number and may convey little or no information about the anti-atherosclerotic properties of HDL in the process of reverse cholesterol. There is evidence to suggest that paradoxical 
increase in HDL-C induced by dietary SFA and cholesterol in mice (Escola-Gil et al. 2011) and in egg-fed humans (Andersen et al. 2013) results in a beneficial increase in cholesterol efflux capacity. Beneficial effects of dietary fatty acids on cholesterol efflux capacity have also been described for EPA and DHA supplementation in hamsters (Kasbi Chadli et al. 2013) and MUFA-rich extra-virgin olive oil consumption in humans (Helal et al. 2013). Conversely, several intervention studies in humans showed no effect on cholesterol efflux capacity of replacing of SFA with either PUFA (Kralova Lesna et al. 2008) or carbohydrate (De Vries et al. 2005), or differences between diets enriched with trans fatty acids (8.3\% energy), SFA (13.2 \% energy) and PUFA (14.6\%) elicited by either total plasma HDL or HDL subfractions (Buonacorso et al. 2007).

In conclusion, evidence from meta-analyses to support the relative effects of dietary fatty acids on HDL-C may be statistically incontrovertible, but they do not necessarily translate directly to the effects of complex foods and diets on HDL-C and CVD risk. Reduction in HDL-C induced by the overconsumption of dietary extrinsic sugars in sugar-sweetened beverages may have major implications for cardiometabolic health, especially in adolescents. Finally, evidence for the effects of dietary components on the anti-atherogenic, functional properties of HDL is inconclusive and warrants further study.

\section{Weight Loss}

Obesity, defined as an excess of body fat, is a major health problem in Western societies (Tchernof and Despres 2013; Bays et al. 2013). Excess body fat is also an independent risk factor for CVD (Tchernof and Despres 2013). Excessive adipose tissue accumulation, but more importantly its distribution in the body, particularly visceral obesity, has been identified as a main correlate of cardiometabolic disorders including not only alterations in glucose tolerance and insulin sensitivity but also in blood lipids, including HDL-C.

\subsection{Impact of Adiposity on HDL Concentration and Function}

Abnormally low plasma HDL-C concentrations accompany hypertriacylglycerolaemia and are a common trait in many obese subjects that contributes to the development of atherosclerosis (Bays et al. 2013; Tchernof and Despres 2013). In obesity, the low plasma HDL-C concentration has been mainly attributed to increased HDL clearance, in part, due to enhanced uptake of HDL by adipocytes (Wang and Peng 2011; Rashid and Genest 2007). Plasma concentrations of larger HDL particles are decreased in patients with high cardiovascular risk (Pirillo et al. 2013) and, similarly, appear to be low in overweight and obese subjects (Tian et al. 2006, 2011). Moreover, a switch towards a higher proportion of smaller HDL particles in relation to larger HDL has been reported in the plasma of obese subjects with ectopic fat and dysfunctional adipose tissue (Tchernof and Despres 
2013). Obesity is commonly associated with increased oxidative stress (Wang and Peng 2011), and, in this context, there may be impairment of HDL functions, including reverse cholesterol transport and protection against lipoprotein oxidation. In this regard, the ability of HDL to mediate cholesterol efflux from cells, which is considered the first step of reverse cholesterol transport (RCT) (Escola-Gil et al. 2009), is reduced in the obese (Sasahara et al. 1998; Vazquez et al. 2012). In addition, although the protection against LDL oxidation conferred by HDL has not been assessed to date, the antioxidant action of apoA-I has been reported to be attenuated in scenarios of increased oxidative stress (Kontush and Chapman 2010), such as that present in obesity (Wang and Peng 2011). Other HDL-associated proteins such as paraoxonase 1 (PON1) and lipoprotein-associated phospholipase A2 (Lp-PLA2), which are also main contributors to the antioxidant properties of HDL (Kontush and Chapman 2010), have been found to be altered in obesity (Seres et al. 2010; da Silva et al. 2013).

\subsection{Effect of Weight-Loss Therapies on HDL Concentration and Function}

Weight loss has been widely thought to be an effective means of achieving a substantial reduction in cardiometabolic risk (Vest et al. 2012). Obesity-associated metabolic disorders can, in theory, be treated by lifestyle modifications including reduced energy intake and/or increased regular, moderate physical activity (Sacks et al. 2009; Bays et al. 2013). A further strategy to achieve excess weight loss in severely obese patients is bariatric surgery (Bays et al. 2013). In particular, the Roux-en-Y gastric bypass (RYGBP) has been reported to induce a sustained weight reduction without relapse in morbidly obese patients. In contrast, the metabolic results of lifestyle interventions are variable and insufficient to achieve sustained weight loss (Vest et al. 2012; Bays et al. 2013), whilst surgery has been shown to stably improve the lipid profile in most randomised, prospective trials (Bays et al. 2013; Vest et al. 2012). However, in both approaches, only modest effects on plasma HDL-C concentrations were reported in most recent systematic reviews and meta-analyses of stabilised weight-loss clinical trials which examined the effects of different dietary (Bays et al. 2013; Chapman et al. 2011; Dattilo and Kris-Etherton 1992; $\mathrm{Hu}$ et al. 2012; Sacks et al. 2009; Schwingshackl and Hoffmann 2013; Singh et al. 2007; Poobalan et al. 2004) or bariatric surgery programmes (Bays et al. 2013; Vest et al. 2012; Poobalan et al. 2004). There are few reports directly assessing the effect of weight reduction on HDL remodelling and its relationship, if any, with its anti-atherogenic properties. In this regard, recent studies showed that weight loss exerts beneficial changes in HDL subpopulations in the obese (Aron-Wisnewsky et al. 2011; Asztalos et al. 2010), leading to a switch towards predominantly larger HDL particles and increased circulating plasma HDL mass despite no significant impact on plasma HDL-C concentrations. Interestingly, in one of these studies, an elevation in HDL mass was strongly associated with an increased capacity of sera from postoperative patients to mediate cholesterol efflux 
via adenosine triphosphate-binding cassette transporter (ABC) G1 and scavenger receptor class-BI (SR-BI) pathways, relative to baseline values (Aron-Wisnewsky et al. 2011), thus suggesting that the removal of excess cholesterol from cells by HDL particles might be enhanced after surgery. Excess weight loss also improves oxidative stress (Uzun et al. 2004; Gletsu-Miller et al. 2009; Rector et al. 2007). However, whilst the impact of weight loss on HDL's antioxidant properties in severely obese patients undergoing bariatric surgery has been reported in observational studies, it has not yet been examined in detail (Gletsu-Miller et al. 2009). For instance, increased PON1 activity levels have been found in serum of patients undergoing gastric surgery (Uzun et al. 2004), whereas the Lp-PLA2 mass concentration did not change in another study (Hanusch-Enserer et al. 2009). Given that the distribution of Lp-PLA2 activity between serum lipoproteins is still uncertain, and evidence to suggest that Lp-PLA2 may be anti-atherogenic when associated with HDL (Kontush and Chapman 2010), it is reasonable to speculate that the increase in plasma concentration of larger HDL particles following weight loss might lead to a proportional increase in anti-atherogenic HDL-associated Lp-PLA2.

Taken together, HDL changes may, in part, account for the significant improvement in the cardiovascular risk observed in obese patients after weight reduction. Thus, in summary, weight loss has long-term beneficial effects on plasma lipids in the obese. Regarding the plasma concentration of HDL-C, the impact of lifestyle interventions appears to be variable and modest in response to different weight-loss treatments. However, data on the effect of weight-reducing lifestyle interventions on the functional properties of HDL are scant. Bariatric surgery is becoming a frequent approach for reducing adiposity and improving the lipid profile in the severely obese. The excess weight loss following intervention may provide an interesting scenario for assessing the potential favourable changes in HDL remodelling and functionality.

\section{Effects of Regular Aerobic Exercise}

Sedentary behaviour is a major health problem that is associated with increased cardiometabolic risk. Regular aerobic physical activity results in improved exercise performance which depends on an increased ability to utilise oxygen to derive energy for work. These effects usually require exercise intensities ranging from 40 to $85 \%$ of maximal oxygen consumption $\left(\mathrm{VO}_{2} \max \right)$ or heart rate reserve, with higher exercise intensities being necessary for higher levels of initial fitness, and vice versa (Chapman et al. 2011).

\subsection{Effects of Exercise on HDL}

Regular aerobic physical activity has a positive effect on many of the established risk factors for CVD by causing a long-lasting reduction in TAGs by up to $20 \%$ and increasing HDL-C by up to $10 \%$. It also increases the size of LDL and HDL particles. All these changes are considered potentially protective against 
atherosclerosis (Kraus et al. 2002; Tall 2002). Given the close interrelation between plasma TAG-rich particles and HDL, changes in HDL-C after regular aerobic exercise are probably dependent on an increased HDL synthesis induced by raised TAG lipolysis (Tall 2002; Olchawa et al. 2004) and, perhaps, also on a reduced HDL catabolism secondary to decreased hepatic lipase (HL) activity (Bergeron et al. 2001).

The effect of physical activity on TAG levels varies depending on baseline TAGs and exercise characteristics such as intensity, caloric expenditure and duration (Chapman et al. 2011; Miller et al. 2011; Kraus et al. 2002; Kodama et al. 2007). The reduction in plasma TAGs of $20 \%$ induced by daily exercise was similar to that obtained by caloric restriction in nonobese subjects (Fontana et al. 2007). Daily exercise blocked, at least in the short term, the increase in TAGs induced by a high-carbohydrate diet in healthy postmenopausal women (Koutsari et al. 2001). Even with a variable adherence to diet, exercise did have a significant effect on plasma TAG and HDL-C levels (Huffman et al. 2012). In healthy, non-smoking men, the increase in HDL-C was dependent on exercise intensity (for instance, miles run per week) (Kokkinos et al. 1995; Tambalis et al. 2009; Duncan et al. 2005), thus suggesting a dose-response relationship. Between 1,200 and 2,200 Kcal of energy expenditure per week (15-20 miles/week of brisk walking or jogging) has been estimated to be the threshold for obtaining a significant change in plasma TAGs and HDL-C (Durstine et al. 2002). The TAG decrease was greater in individuals with fasting TAGs $>1.69 \mathrm{mmol} / \mathrm{L}$ than in those with TAGs $<1.69 \mathrm{mmol} / \mathrm{L}$ (Couillard et al. 2001). HDL-C increased, particularly in men with TAGs $>1.69 \mathrm{mmol} / \mathrm{L}$ and low HDL-C, compared with those with low HDL-C and TAGs $<1.69 \mathrm{mmol} / \mathrm{L}$, and was associated with a reduction in abdominal adipose tissue (Couillard et al. 2001). This improvement may have been associated with decreased insulin resistance, adiposity and TAG levels, at least in part, through increased fatty acid oxidation by the muscle under the control of Reverb-alpha (Tall 2002; Woldt et al. 2013). Whilst data regarding the changes in HDL functionality induced by regular aerobic training are to date scant and inconsistent, there is evidence to implicate beneficial changes in some functions of HDL (Iborra et al. 2008; Kazeminasab et al. 2013; Meissner et al. 2010, 2011).

\subsection{Effects of Exercise on Prevention and Treatment of Cardiometabolic Risk}

Obviously, exercise exerts many different effects at a molecular level, rendering it very difficult to attribute the final effects on disease prevention or treatment to one effect, including HDL-C.

Several prospective cohort trials have shown a reduction in the risk of type 2 diabetes in individuals participating in physical activity of moderate intensity compared with being sedentary (Wing 2010; Uusitupa et al. 2009). This difference was also found in people who walked regularly (typically $>2.5 \mathrm{~h}$ of brisk walking) (reviewed by Jeon et al. 2007). 
Regular aerobic exercise is widely considered an important tool for primary and secondary cardiovascular prevention since it is thought to reduce the risk of fatal and nonfatal events in the general population (Chapman et al. 2011; Heran et al. 2011). Although the volume of moderate-intensity physical activity able to provide a reduction in cardiovascular mortality was initially considered to range from 2.5 to $5 \mathrm{~h}$ /week, similar results appear to be obtainable with 1-1.5 h/week of vigorous-intensity or a combination of vigorous- and moderate-intensity exercises (Wen et al. 2011; Sattelmair et al. 2011). However, a systematic review of exercisebased rehabilitation found a decrease in total and cardiovascular mortality but no difference in the number of new myocardial infarctions (Heran et al. 2011). Further, the Look AHEAD Trial which had, as a goal, to achieve and maintain a weight loss of at least $7 \%$ by both reducing caloric intake and increasing physical activity in type 2 diabetic patients found no reduction in cardiovascular events in a 10-year follow-up (Wing et al. 2013). Similar negative results were obtained by the Finnish Diabetes Prevention Study after a 10-year lifestyle intervention (diet + exercise) in middle-aged, overweight people with impaired glucose tolerance (Uusitupa et al. 2009). To interpret these discrepant results, one has to consider differences in patient disease (type 2 diabetes versus established coronary artery disease) versus the general population, follow-up time and patient intervention type(s) (Sattelmair et al. 2011; Wen et al. 2011; Heran et al. 2011; Uusitupa et al. 2009).

Exercise improved the components of the metabolic syndrome in affected patients (Pattyn et al. 2013). In patients with established type 2 diabetes mellitus included in the Look AHEAD Trial, increased physical activity had beneficial effects on glycaemic control and cardiovascular risk factors, including HDL-C and TAGs (Wing 2010). However, in other studies, aerobic and/or resistance training was shown to improve glycaemic control, but did not change HDL-C or TAGs in adults with type 2 diabetes (Sigal et al. 2007). There were major differences in the number of patients and follow-up time between studies that should be considered when interpreting these different results (Wing 2010; Sigal et al. 2007). Furthermore, one study included a hypo-caloric diet together with exercise (Wing 2010), whereas the other only included exercise (Sigal et al. 2007).

In summary, there appears to be a consensus that regular aerobic exercise raises HDL-C in a way closely related to plasma TAG reduction. Regular aerobic exercise may prevent type 2 diabetes and CVD, probably with more intensity in primary than in secondary prevention. In particular, aerobic exercise does not seem to prevent CVD in patients with established type 2 diabetes. The role of exercise-induced changes in HDL in these outcomes is largely unknown.

\section{$4 \quad$ Smoking Cessation}

Smoking is a well-documented risk factor for CVD that is amenable to intervention. A potential mechanism for the atherogenic effect of cigarette smoke is via plasma HDL. Most research to date has looked at smoking effects on HDL-C concentration rather than HDL structure or function. One issue that is particularly difficult to address in observational smoking research is the presence of confounding lifestyle 
behaviours that may cluster with smoking behaviour (such as low physical activity, poor diet and increased alcohol consumption). Thus, comparison of the properties of HDL isolated from smokers and non-smokers does not allow direct causal relationships to be determined, and there is a need for more direct experimental approaches to dissect the biological effects of smoking and to identify specific mediating factors (i.e. the combustible products of tobacco such as nicotine, carbon monoxide and other gaseous products and free radicals). To further complicate the issue, smoking has effects on TAG metabolism, via increased sympathetic drive, insulin resistance or both, leading to increased plasma TAG concentrations and consequent remodelling effects of plasma HDL resulting in higher plasma turnover [reviewed in Freeman and Packard (1995)].

\subsection{Smoking and HDL-C Concentration}

A meta-analysis carried out almost 25 years ago indicated that smoking has a strong independent effect on plasma HDL-C levels with smokers having on average $6 \%$ lower HDL-C concentrations compared to non-smokers (Craig et al. 1989). A more recent meta-analysis, which compared within individual differences before and after stopping smoking, indicated that the absolute HDL-C concentration difference was between 0.06 and $0.11 \mathrm{mmol} / \mathrm{L}$ (Forey et al. 2013). There also appears to be a larger smoking effect in women than men (Freeman and Packard 1995). HDL-C concentrations rise after stopping smoking and fall on restarting, and the magnitude of the effect on HDL-C is related to the number of cigarettes smoked (Fortmann et al. 1986; Moffatt et al. 1995; Stubbe et al. 1982; Tuomilehto et al. 1986). There are no long-lasting effects of smoking on HDL-C concentration after cessation (Forey et al. 2013), and there is no association between number of years stopped and plasma HDL-C (Wilson et al. 1983). Passive smoking is also associated with lower plasma HDL (Moffatt et al. 1995; Neufeld et al. 1997), and a reduction in HDL-C has been observed acutely only $6 \mathrm{~h}$ after exposure to environmental tobacco smoke (Moffatt et al. 2004). The reduction in plasma HDL-C levels appears to be limited to a $0.15 \mathrm{mmol} / \mathrm{L}$ reduction in the larger HDL2 particles, independent of confounders, as determined by analytical ultracentrifugation (Freeman et al. 1993). This has been confirmed by others (Moriguchi et al. 1991; Shennan et al. 1985; Moffatt et al. 2004), although one study attributed the acute effects of smoking to the smaller HDL3 fraction (Gnasso et al. 1984). Plasma apoA-I levels are also $6 \%$ lower in smokers (Craig et al. 1989), and in some studies apoA-II has also been shown to be reduced in smokers (Berg et al. 1979; Haffner et al. 1985) and ex-smokers (Richard et al. 1997).

\subsection{Potential Mechanisms for the Smoking-Related Reduction in HDL-C}

Because of the intrinsic link between plasma TAG and HDL metabolism, demonstrated by their negative association in populations, and the biological effects of smoking on plasma TAG metabolism (Freeman and Packard 1995), it is likely 
that changes in plasma HDL-C concentration could be an indirect effect of smoking-related increases in plasma TAG concentration. Indeed, much of the effect of smoking on plasma HDL is lost after statistical correction for changes in plasma TAGs (Freeman et al. 1993; Phillips et al. 1981). Cigarette smoking affects the activities of plasma enzymes involved in regulating HDL size and turnover: lecithin-cholesterol acyltransferase (LCAT) (Freeman et al. 1998; Haffner et al. 1985) and lipoprotein lipase (LPL) (Freeman et al. 1998; Elkeles et al. 1983) activities are reduced, whilst HL (Moriguchi et al. 1991) and CETP (Dullaart et al. 1994) activities are increased. These changes result in a shift in the size distribution of HDL into smaller particles which have increased clearance from the plasma compartment (Brinton et al. 1994). However, there is a residual effect of smoking after correction for changes in plasma TAG, suggesting TAG-independent effects of smoking on plasma HDL concentration also exist. These TAG-independent effects appear to be more important in men than women (Freeman et al. 1993).

There is evidence for structural/compositional changes in HDL brought about by smoking. Ex vivo experiments, in which human plasma was acutely exposed to cigarette smoke, resulted in cross-linking of apoA-I and apoA-II (McCall et al. 1994) that may impair activation of LCAT. Similarly, chemically crosslinked HDL has an increased clearance in rodents (Senault et al. 1990). Smoking is associated with a reduction in the HDL content of Lp-PLA2, an enzyme thought to play an anti-atherogenic role in HDL (Tselepis et al. 2009). Early studies showed that chronic inhalation of cigarette smoke in pigeons inhibits liver HDL uptake (Mulligan et al. 1983). Recent data have shown that a by-product of cigarette smoking, benzo(a)pyrene, inhibited apoA-I synthesis in HepG2 cells, via activation of the aryl hydrocarbon nuclear steroid receptor, whilst nicotine had no effect (Naem et al. 2012). Modelling of the monocyte transcriptome in smokers compared to non-smokers identified SLC39A8 to be on a causal pathway between smoking and plaque formation (Verdugo et al. 2013). This gene is known to be associated with the cellular uptake of cadmium from tobacco and was negatively associated with HDL cholesterol levels in this study.

There are very few studies on the effects of smoking on HDL function. HDL isolated from smokers showed reduced ability to induce cholesterol efflux from macrophages, possibly via apoA-I-mediated effects (Kralova Lesna et al. 2012). Ex vivo cigarette smoke treated HDL, which resulted in an increased conjugated diene and denatured apoA-I content, reduced the efflux capacity of HDL to a level similar to that of copper-oxidised HDL (Ueyama et al. 1998). Co-incubation with superoxide dismutase prevented approximately half of the impairment and reduced the level of conjugated dienes, but not the apoA-I denaturation. There is also some evidence that plasma thiocyanates found in high levels in smokers could cause HDL oxidation and reduced apoA-I cholesterol efflux ability (Hadfield et al. 2013). Smoking is associated with reduced activity and concentration of PON1, an HDL-associated antioxidant enzyme, effects which are reversed after smoking cessation (James et al. 2000). The mechanistic data for the effects of smoking on HDL function are far from comprehensive and merit further investigation. 


\subsection{Smoking Cessation Intervention to Increase Plasma HDL Concentration}

The majority of smoking cessation studies are small, and most, but not all, have been shown to result in a rise in HDL concentration. A meta-analysis of 27 studies incorporating over 6,000 subjects indicated that HDL-C increased by $0.10 \mathrm{mmol} / \mathrm{L}$ after smoking cessation, whilst plasma total cholesterol, LDL-C and TAG did not change (Maeda et al. 2003).

A number of lifestyle changes may also occur when smokers cease smoking, and at least one study has shown that the rise in HDL after smoking cessation is not independent of the change in diet (Quensel et al. 1989b). However, refuting this, a recent large randomised, double-blind controlled trial was carried out in over 1,500 smokers smoking an average of 21 cigarettes per day (Gepner et al. 2011). Patients were randomised to one of six treatments: nicotine lozenge, nicotine patch, sustained-release bupropion, nicotine patch plus nicotine lozenge, sustained-release bupropion plus nicotine lozenge, or placebo. Of the 923 participants who returned after 1 year intervention, $36 \%$ who had stopped smoking showed a significantly greater rise in HDL-C than those who did not, despite gaining an average of $4 \mathrm{~kg}$ more weight than those who continued to smoke. The effects of smoking cessation in this study were particularly evident in women.

Transdermal nicotine replacement therapy is a commonly used approach to support smoking cessation. A small study was carried out to compare the effects of transdermal nicotine patches, used as part of a smoking cessation intervention, on plasma HDL-C levels (Moffatt et al. 2000). Subjects who used transdermal nicotine patches over 35 days showed no improvement in HDL-C concentration. However, if the use of patches was then stopped, HDL-C concentrations rose to normal, non-smoking levels over the next 42 days. Others have observed contrasting effects in a larger study where smoking cessation, accompanied by the use of higher-dose nicotine transdermal patches, resulted in an immediate increase in HDL, whereas in contrast, low-dose nicotine did not (Allen et al. 1994). These latter findings are somewhat contradictory to data indicating that nicotine administration to non-smokers, via chewing gum, does not affect HDL-C levels (Quensel et al. 1989a). The potential effects of nicotine patches during smoking cessation on plasma HDL have yet to be clarified.

In summary, smoking leads to a reduction in plasma HDL-C, HDL2-C, apo A-I and probably apoA-II concentrations. The effects of smoking on HDL are dose dependent and reversed upon smoking cessation. Much of the effect of smoking may be TAG dependent where increased plasma TAG concentration leads to remodelling of HDL to a smaller particle size which is more rapidly cleared from the circulation. TAG-independent effects have not yet been thoroughly investigated but include modification of apoA-I, reductions in HDL antioxidant enzyme activity and reduced ability of HDL to promote cholesterol efflux. The effect of nicotine aids, used to support smoking cessation interventions, on HDL-C concentration and function is unclear. 


\section{Effects of Alcohol on HDL and Cardiovascular Risk}

Multiple studies have established a known J-shaped relationship between alcohol intake and cardiovascular risk including coronary heart disease and ischaemic stroke (Krenz and Korthuis 2012). The term 'drink' is imprecise; however, the amount of alcohol in one drink is similar for wine, spirits or beer. Thus, a $100 \mathrm{ml}$ glass of table wine at $13 \%$ alcohol, $35 \mathrm{ml}$ of distilled spirits at $40 \%$ alcohol and $300 \mathrm{ml}$ of beer at $5 \%$ alcohol all contain around 10-12 $\mathrm{g}$ of pure ethyl alcohol. The general consensus is that men consuming two standard alcoholic drinks per day and women consuming half that intake appear to have a lower cardiovascular event rate than persons abstaining from alcohol (Krenz and Korthuis 2012). Estimates of the risk reduction associated with moderate alcohol intake drinkers compared with those abstaining from alcohol range from 25 to $30 \%$ (Krenz and Korthuis 2012).

\subsection{Alcohol Intake and HDL-C}

Several plausible mechanisms have been proposed to explain the positive moderate alcohol intake-mediated effects on CVDs: reduced thrombogenic and coagulation factors (platelet aggregation and fibrinogen levels), low plasma concentrations of inflammation markers (C-reactive protein, interleukin-6 and adiponectin), lowered blood pressure, increased insulin sensitivity and lipoprotein profile via a lowering of LDL-C and increase in HDL-C (Klatsky 2010). However, this alcohol-CVD relationship is nonlinear, and excessive alcohol consumption has adverse effects on hypertension and other pro-inflammatory factors, despite increasing HDL-C (Foerster et al. 2009).

Some reports have suggested that wine carries a lower risk of mortality than beer or spirits and that this may be related to the ability of nonalcoholic phenolic compounds to inhibit LDL oxidation and its pro-inflammatory effects (Frankel et al. 1993; Gronbaek et al. 2000; Klatsky et al. 2003). However, other studies have failed to identify an additional advantage associated with red wine (Di Castelnuovo et al. 2002; Mukamal et al. 2003), thereby suggesting that ethyl alcohol is the main factor for the cardioprotective effect.

A recent meta-analysis demonstrated that alcohol exerts favourable effects on several cardiovascular biomarkers (higher HDL-C, apoA-I and adiponectin levels and lower fibrinogen levels) which seems to be independent of the alcoholic beverage type (Brien et al. 2011). This systematic review found that 1-2 drinks per day increased HDL-C by $0.10 \mathrm{mmol} / \mathrm{L}$ (Brien et al. 2011). However, the contribution of alcohol-induced HDL-C-raising effects to cardiovascular risk remains largely unknown. Early studies indicated that the atheroprotective effects were mediated, largely, by the increase in HDL-C, since the addition of HDL-C to the multivariate model attenuated the inverse association between alcohol intake and myocardial infarction (Gaziano et al. 1993). Nevertheless, one recent report describing a large Norwegian cohort with extensive control for confounding factors showed that HDL-C levels were not on the causal pathway connecting alcohol to 
the lower risk of death from coronary heart disease (Magnus et al. 2011). These findings raise the question of which specific HDL subpopulation particles are affected by alcohol intake and their significance for coronary heart disease protection.

\subsection{Effects of Alcohol on HDL Atheroprotective Functions}

Studies on the effect of alcohol consumption on HDL particle size are inconsistent. In some studies, moderate alcohol consumption increased small HDL subfractions, mainly HDL3 (Haskell et al. 1984; Gardner et al. 2000; Nishiwaki et al. 1994), and lipid-poor pre $\beta$-HDL particles (Beulens et al. 2004). These effects on HDL size could be related to the ability of alcohol to stimulate LPL activity (Nishiwaki et al. 1994). However, other studies on moderate drinkers found increased concentrations of both HDL2 and HDL3 (Gaziano et al. 1993; Clevidence et al. 1995; De Oliveira et al. 2000), and human kinetic studies demonstrated that moderate alcohol consumption resulted in dose-dependent increases in HDL-C, apoA-I and apoA-II through an increase in the HDL apolipoprotein transport rate, but without altering their catabolic rate and LPL activity (De Oliveira et al. 2000). These changes might explain the ability of HDL from moderate alcohol drinkers to enhance macrophage cholesterol efflux (Beulens et al. 2004). However, cholesterol efflux was also enhanced in heavy drinkers who usually show larger HDL (Makela et al. 2008); these changes were associated with decreased CETP activity and increased phospholipid transfer protein (PLTP) activity (Makela et al. 2008). It should be noted that these macrophage cholesterol efflux assays only quantified the first-step RCT pathway without addressing the efficiency of the rest of the RCT steps or the other HDL cardioprotective functions. Nevertheless, moderate alcohol intake was not associated with changes in the activities of other HDL remodelling factors, such as LCAT or CETP (Nishiwaki et al. 1994; Riemens et al. 1997; Sierksma et al. 2004), and, furthermore, the ability of HDL to deliver cholesterol into the liver cells seemed to be decreased in both moderate and heavy drinkers (Rao et al. 2000; Marmillot et al. 2007).

Beyond the RCT pathway, moderate alcohol consumption increased serum PON1 (van der Gaag et al. 1999; Sierksma et al. 2002; Rao et al. 2003), along with liver PON1 mRNA levels (Rao et al. 2003), although this effect was not found in one study with moderate red wine drinkers (Sarandol et al. 2003). In contrast, heavy alcohol drinking produced the opposite effects (Rao et al. 2003). Furthermore, alcohol promotes the conversion of phosphatidylcholine into phosphatidylethanol, and it was reported that HDL-associated phosphatidylethanol increased endothelial secretion of the vascular endothelial growth factor (Liisanantti and Savolainen 2009), which could partly explain the positive effect of alcohol on angiogenesis induction.

In summary, the inverse relationship between moderate and regular alcohol intake and cardiovascular risk as well as the ability of alcohol to increase HDL-C is well documented in the literature. Although some studies reported favourable 
effects of alcohol on HDL cardioprotective functions, it is unclear how many of the alcohol-mediated cardioprotective effects were mediated by the HDL increase. Finally, the American Heart Association recommendation that alcoholic beverage consumption should be limited to no more than 2 drinks per day for men and 1 drink per day for women and should be consumed with meals should be taken into account. Alcohol should not be considered a therapeutic option for cardiovascular risk reduction (Lichtenstein et al. 2006).

Acknowledgements This work was partly funded by European Cooperation in Science and Technology (COST) action BM0904, Ministerio de Sanidad y Consumo, Instituto de Salud Carlos III, FIS 10-00277 and CP13-00070 (to J.J.), FIS 11-0176 (to F.V-B.) and FIS 12-00291 (to J.C.EG). CIBER de Diabetes y Enfermedades Metabólicas Asociadas is an Instituto de Salud Carlos III Project.

Open Access This chapter is distributed under the terms of the Creative Commons Attribution Noncommercial License, which permits any noncommercial use, distribution, and reproduction in any medium, provided the original author(s) and source are credited.

\section{References}

Allen SS, Hatsukami D, Gorsline J (1994) Cholesterol changes in smoking cessation using the transdermal nicotine system. Transdermal nicotine study group. Prev Med 23(2):190-196

Ambrosini GL, Oddy WH, Huang RC, Mori TA, Beilin LJ, Jebb SA (2013) Prospective associations between sugar-sweetened beverage intakes and cardiometabolic risk factors in adolescents. Am J Clin Nutr 98(2):327-334

Andersen CJ, Blesso CN, Lee J, Barona J, Shah D, Thomas MJ, Fernandez ML (2013) Egg consumption modulates HDL lipid composition and increases the cholesterol-accepting capacity of serum in metabolic syndrome. Lipids 48(6):557-567

Aron-Wisnewsky J, Julia Z, Poitou C, Bouillot JL, Basdevant A, Chapman MJ, Clement K, Guerin M (2011) Effect of bariatric surgery-induced weight loss on SR-BI-, ABCG1-, and ABCA1mediated cellular cholesterol efflux in obese women. J Clin Endocrinol Metab 96 (4):1151-1159

Astrup A, Dyerberg J, Elwood P, Hermansen K, Hu FB, Jakobsen MU, Kok FJ, Krauss RM, Lecerf JM, LeGrand P, Nestel P, Riserus U, Sanders T, Sinclair A, Stender S, Tholstrup T, Willett WC (2011) The role of reducing intakes of saturated fat in the prevention of cardiovascular disease: where does the evidence stand in 2010? Am J Clin Nutr 93(4):684-688

Asztalos BF, Swarbrick MM, Schaefer EJ, Dallal GE, Horvath KV, Ai M, Stanhope KL, Austrheim-Smith I, Wolfe BM, Ali M, Havel PJ (2010) Effects of weight loss, induced by gastric bypass surgery, on HDL remodeling in obese women. J Lipid Res 51(8):2405-2412

Bays HE, Toth PP, Kris-Etherton PM, Abate N, Aronne LJ, Brown WV, Gonzalez-Campoy JM, Jones SR, Kumar R, La Forge R, Samuel VT (2013) Obesity, adiposity, and dyslipidemia: a consensus statement from the National Lipid Association. J Clin Lipidol 7(4):304-383

Belsey J, de Lusignan S, Chan T, van Vlymen J, Hague N (2008) Abnormal lipids in high-risk patients achieving cholesterol targets: a cross-sectional study of routinely collected UK general practice data. Curr Med Res Opin 24(9):2551-2560

Berg K, Borresen AL, Dahlen G (1979) Effect of smoking on serum levels of HDL apoproteins. Atherosclerosis 34(3):339-343

Bergeron J, Couillard C, Despres JP, Gagnon J, Leon AS, Rao DC, Skinner JS, Wilmore JH, Bouchard C (2001) Race differences in the response of postheparin plasma lipoprotein lipase 
and hepatic lipase activities to endurance exercise training in men: results from the HERITAGE Family Study. Atherosclerosis 159(2):399-406

Beulens JW, Sierksma A, van Tol A, Fournier N, van Gent T, Paul JL, Hendriks HF (2004) Moderate alcohol consumption increases cholesterol efflux mediated by ABCA1. J Lipid Res 45(9):1716-1723

Brien SE, Ronksley PE, Turner BJ, Mukamal KJ, Ghali WA (2011) Effect of alcohol consumption on biological markers associated with risk of coronary heart disease: systematic review and meta-analysis of interventional studies. BMJ 342:d636

Brinton EA, Eisenberg S, Breslow JL (1994) Human HDL cholesterol levels are determined by apoA-I fractional catabolic rate, which correlates inversely with estimates of HDL particle size. Effects of gender, hepatic and lipoprotein lipases, triglyceride and insulin levels, and body fat distribution. Arterioscler Thromb 14(5):707-720

Buonacorso V, Nakandakare ER, Nunes VS, Passarelli M, Quintao EC, Lottenberg AM (2007) Macrophage cholesterol efflux elicited by human total plasma and by HDL subfractions is not affected by different types of dietary fatty acids. Am J Clin Nutr 86(5):1270-1277

Chapman MJ, Ginsberg HN, Amarenco P, Andreotti F, Boren J, Catapano AL, Descamps OS, Fisher E, Kovanen PT, Kuivenhoven JA, Lesnik P, Masana L, Nordestgaard BG, Ray KK, Reiner Z, Taskinen MR, Tokgozoglu L, Tybjaerg-Hansen A, Watts GF (2011) Triglyceriderich lipoproteins and high-density lipoprotein cholesterol in patients at high risk of cardiovascular disease: evidence and guidance for management. Eur Heart J 32(11):1345-1361

Clevidence BA, Reichman ME, Judd JT, Muesing RA, Schatzkin A, Schaefer EJ, Li Z, Jenner J, Brown CC, Sunkin M et al (1995) Effects of alcohol consumption on lipoproteins of premenopausal women. A controlled diet study. Arterioscler Thromb Vasc Biol 15(2):179-184

Couillard C, Despres JP, Lamarche B, Bergeron J, Gagnon J, Leon AS, Rao DC, Skinner JS, Wilmore JH, Bouchard C (2001) Effects of endurance exercise training on plasma HDL cholesterol levels depend on levels of triglycerides: evidence from men of the Health, Risk Factors, Exercise Training and Genetics (HERITAGE) Family Study. Arterioscler Thromb Vasc Biol 21(7):1226-1232

Craig WY, Palomaki GE, Haddow JE (1989) Cigarette smoking and serum lipid and lipoprotein concentrations: an analysis of published data. BMJ 298(6676):784-788

da Silva IT, Timm Ade S, Damasceno NR (2013) Influence of obesity and cardiometabolic makers on lipoprotein-associated phospholipase A2 (Lp-PLA2) activity in adolescents: the healthy young cross-sectional study. Lipids Health Dis 12:19

Dattilo AM, Kris-Etherton PM (1992) Effects of weight reduction on blood lipids and lipoproteins: a meta-analysis. Am J Clin Nutr 56(2):320-328

De Oliveira ESER, Foster D, McGee Harper M, Seidman CE, Smith JD, Breslow JL, Brinton EA (2000) Alcohol consumption raises HDL cholesterol levels by increasing the transport rate of apolipoproteins A-I and A-II. Circulation 102(19):2347-2352

De Vries R, Beusekamp BJ, Kerstens MN, Groen AK, Van Tol A, Dullaart RP (2005) A low-saturated-fat, low-cholesterol diet decreases plasma CETP activity and pre beta-HDL formation but does not affect cellular cholesterol efflux to plasma from type 1 diabetic patients. Scand J Clin Lab Invest 65(8):729-737

Di Castelnuovo A, Rotondo S, Iacoviello L, Donati MB, De Gaetano G (2002) Meta-analysis of wine and beer consumption in relation to vascular risk. Circulation 105(24):2836-2844

Dullaart RP, Hoogenberg K, Dikkeschei BD, van Tol A (1994) Higher plasma lipid transfer protein activities and unfavorable lipoprotein changes in cigarette-smoking men. Arterioscler Thromb 14(10):1581-1585

Duncan GE, Anton SD, Sydeman SJ, Newton RL Jr, Corsica JA, Durning PE, Ketterson TU, Martin AD, Limacher MC, Perri MG (2005) Prescribing exercise at varied levels of intensity and frequency: a randomized trial. Arch Intern Med 165(20):2362-2369

Durstine JL, Grandjean PW, Cox CA, Thompson PD (2002) Lipids, lipoproteins, and exercise. J Cardiopulm Rehabil 22(6):385-398 
Elkeles RS, Khan SR, Chowdhury V, Swallow MB (1983) Effects of smoking on oral fat tolerance and high density lipoprotein cholesterol. Clin Sci (Lond) 65(6):669-672

Escola-Gil JC, Rotllan N, Julve J, Blanco-Vaca F (2009) In vivo macrophage-specific RCT and antioxidant and antiinflammatory HDL activity measurements: new tools for predicting HDL atheroprotection. Atherosclerosis 206(2):321-327

Escola-Gil JC, Llaverias G, Julve J, Jauhiainen M, Mendez-Gonzalez J, Blanco-Vaca F (2011) The cholesterol content of Western diets plays a major role in the paradoxical increase in highdensity lipoprotein cholesterol and upregulates the macrophage reverse cholesterol transport pathway. Arterioscler Thromb Vasc Biol 31(11):2493-2499

Foerster M, Marques-Vidal P, Gmel G, Daeppen JB, Cornuz J, Hayoz D, Pecoud A, Mooser V, Waeber G, Vollenweider P, Paccaud F, Rodondi N (2009) Alcohol drinking and cardiovascular risk in a population with high mean alcohol consumption. Am J Cardiol 103(3):361-368

Fontana L, Villareal DT, Weiss EP, Racette SB, Steger-May K, Klein S, Holloszy JO (2007) Calorie restriction or exercise: effects on coronary heart disease risk factors. A randomized, controlled trial. Am J Physiol Endocrinol Metab 293(1):E197-E202

Forey BA, Fry JS, Lee PN, Thornton AJ, Coombs KJ (2013) The effect of quitting smoking on HDL-cholesterol - a review based on within-subject changes. Biomark Res 1(1):26

Fortmann SP, Haskell WL, Williams PT (1986) Changes in plasma high density lipoprotein cholesterol after changes in cigarette use. Am J Epidemiol 124(4):706-710

Frankel EN, Kanner J, German JB, Parks E, Kinsella JE (1993) Inhibition of oxidation of human low-density lipoprotein by phenolic substances in red wine. Lancet 341(8843):454-457

Freeman DJ, Packard CJ (1995) Smoking and plasma lipoprotein metabolism. Clin Sci (Lond) 89 (4):333-342

Freeman DJ, Griffin BA, Murray E, Lindsay GM, Gaffney D, Packard CJ, Shepherd J (1993) Smoking and plasma lipoproteins in man: effects on low density lipoprotein cholesterol levels and high density lipoprotein subfraction distribution. Eur J Clin Invest 23(10):630-640

Freeman DJ, Caslake MJ, Griffin BA, Hinnie J, Tan CE, Watson TD, Packard CJ, Shepherd J (1998) The effect of smoking on post-heparin lipoprotein and hepatic lipase, cholesteryl ester transfer protein and lecithin:cholesterol acyl transferase activities in human plasma. Eur J Clin Invest 28(7):584-591

Frost G, Leeds AA, Dore CJ, Madeiros S, Brading S, Dornhorst A (1999) Glycaemic index as a determinant of serum HDL-cholesterol concentration. Lancet 353(9158):1045-1048

Gardner CD, Tribble DL, Young DR, Ahn D, Fortmann SP (2000) Associations of HDL, HDL(2), and HDL(3) cholesterol and apolipoproteins A-I and B with lifestyle factors in healthy women and men: the Stanford Five City Project. Prev Med 31(4):346-356

Gaziano JM, Buring JE, Breslow JL, Goldhaber SZ, Rosner B, VanDenburgh M, Willett W, Hennekens CH (1993) Moderate alcohol intake, increased levels of high-density lipoprotein and its subfractions, and decreased risk of myocardial infarction. N Engl J Med 329 (25): $1829-1834$

Gepner AD, Piper ME, Johnson HM, Fiore MC, Baker TB, Stein JH (2011) Effects of smoking and smoking cessation on lipids and lipoproteins: outcomes from a randomized clinical trial. Am Heart J 161(1):145-151

Gletsu-Miller N, Hansen JM, Jones DP, Go YM, Torres WE, Ziegler TR, Lin E (2009) Loss of total and visceral adipose tissue mass predicts decreases in oxidative stress after weight-loss surgery. Obesity (Silver Spring) 17(3):439-446

Gnasso A, Haberbosch W, Schettler G, Schmitz G, Augustin J (1984) Acute influence of smoking on plasma lipoproteins. Klin Wochenschr 62(Suppl 2):36-42

Goyens PL, Mensink RP (2006) Effects of alpha-linolenic acid versus those of EPA/DHA on cardiovascular risk markers in healthy elderly subjects. Eur J Clin Nutr 60(8):978-984

Griffin MD, Sanders TA, Davies IG, Morgan LM, Millward DJ, Lewis F, Slaughter S, Cooper JA, Miller GJ, Griffin BA (2006) Effects of altering the ratio of dietary n-6 to n-3 fatty acids on insulin sensitivity, lipoprotein size, and postprandial lipemia in men and postmenopausal women aged 45-70 y: the OPTILIP Study. Am J Clin Nutr 84(6):1290-1298 
Groener JE, van Ramshorst EM, Katan MB, Mensink RP, van Tol A (1991) Diet-induced alteration in the activity of plasma lipid transfer protein in normolipidemic human subjects. Atherosclerosis 87(2-3):221-226

Gronbaek M, Becker U, Johansen D, Gottschau A, Schnohr P, Hein HO, Jensen G, Sorensen TI (2000) Type of alcohol consumed and mortality from all causes, coronary heart disease, and cancer. Ann Intern Med 133(6):411-419

Grundy SM, Denke MA (1990) Dietary influences on serum lipids and lipoproteins. J Lipid Res 31 (7):1149-1172

Hadfield KA, Pattison DI, Brown BE, Hou L, Rye KA, Davies MJ, Hawkins CL (2013) Myeloperoxidase-derived oxidants modify apolipoprotein A-I and generate dysfunctional high-density lipoproteins: comparison of hypothiocyanous acid (HOSCN) with hypochlorous acid (HOCl). Biochem J 449(2):531-542

Haffner SM, Applebaum-Bowden D, Wahl PW, Hoover JJ, Warnick GR, Albers JJ, Hazzard WR (1985) Epidemiological correlates of high density lipoprotein subfractions, apolipoproteins A-I, A-II, and D, and lecithin cholesterol acyltransferase. Effects of smoking, alcohol, and adiposity. Arteriosclerosis 5(2):169-177

Hanusch-Enserer U, Zorn G, Wojta J, Kopp CW, Prager R, Koenig W, Schillinger M, Roden M, Huber K (2009) Non-conventional markers of atherosclerosis before and after gastric banding surgery. Eur Heart J 30(12):1516-1524

Harper CR, Edwards MC, Jacobson TA (2006) Flaxseed oil supplementation does not affect plasma lipoprotein concentration or particle size in human subjects. J Nutr 136(11):2844-2848

Harris WS (1989) Fish oils and plasma lipid and lipoprotein metabolism in humans: a critical review. J Lipid Res 30(6):785-807

Harris WS (1997) n-3 fatty acids and serum lipoproteins: human studies. Am J Clin Nutr 65 (5 Suppl):1645S-1654S

Haskell WL, Camargo C Jr, Williams PT, Vranizan KM, Krauss RM, Lindgren FT, Wood PD (1984) The effect of cessation and resumption of moderate alcohol intake on serum highdensity-lipoprotein subfractions. A controlled study. N Engl J Med 310(13):805-810

Helal O, Berrougui H, Loued S, Khalil A (2013) Extra-virgin olive oil consumption improves the capacity of HDL to mediate cholesterol efflux and increases ABCA1 and ABCG1 expression in human macrophages. Br J Nutr 109(10):1844-1855

Heran BS, Chen JM, Ebrahim S, Moxham T, Oldridge N, Rees K, Thompson DR, Taylor RS (2011) Exercise-based cardiac rehabilitation for coronary heart disease. Cochrane Database Syst Rev 7, CD001800

Hu T, Mills KT, Yao L, Demanelis K, Eloustaz M, Yancy WS Jr, Kelly TN, He J, Bazzano LA (2012) Effects of low-carbohydrate diets versus low-fat diets on metabolic risk factors: a metaanalysis of randomized controlled clinical trials. Am J Epidemiol 176(Suppl 7):S44-S54

Huffman KM, Hawk VH, Henes ST, Ocampo CI, Orenduff MC, Slentz CA, Johnson JL, Houmard JA, Samsa GP, Kraus WE, Bales CW (2012) Exercise effects on lipids in persons with varying dietary patterns-does diet matter if they exercise? Responses in Studies of a Targeted Risk Reduction Intervention through Defined Exercise I. Am Heart J 164(1):117-124

Iborra RT, Ribeiro IC, Neves MQ, Charf AM, Lottenberg SA, Negrao CE, Nakandakare ER, Passarelli M (2008) Aerobic exercise training improves the role of high-density lipoprotein antioxidant and reduces plasma lipid peroxidation in type 2 diabetes mellitus. Scand J Med Sci Sports 18(6):742-750

James RW, Leviev I, Righetti A (2000) Smoking is associated with reduced serum paraoxonase activity and concentration in patients with coronary artery disease. Circulation 101 (19):2252-2257

Jeon CY, Lokken RP, Hu FB, van Dam RM (2007) Physical activity of moderate intensity and risk of type 2 diabetes: a systematic review. Diabetes Care 30(3):744-752

Kasbi Chadli F, Nazih H, Krempf M, Nguyen P, Ouguerram K (2013) Omega 3 fatty acids promote macrophage reverse cholesterol transport in hamster fed high fat diet. PLoS ONE 8 (4):e61109 
Katan MB, Grundy SM, Willett WC (1997) Should a low-fat, high-carbohydrate diet be recommended for everyone? Beyond low-fat diets. N Engl J Med 337(8):563-566, discussion 566-567

Kaul N, Kreml R, Austria JA, Richard MN, Edel AL, Dibrov E, Hirono S, Zettler ME, Pierce GN (2008) A comparison of fish oil, flaxseed oil and hempseed oil supplementation on selected parameters of cardiovascular health in healthy volunteers. J Am Coll Nutr 27(1):51-58

Kazeminasab F, Marandi M, Ghaedi K, Esfarjani F, Moshtaghian J (2013) Endurance training enhances LXRalpha gene expression in Wistar male rats. Eur J Appl Physiol 113 (9):2285-2290

Keys A (1980a) Alpha lipoprotein (HDL) cholesterol in the serum and the risk of coronary heart disease and death. Lancet 2(8195 pt 1):603-606

Keys A (1980b) W. O. Atwater memorial lecture: overweight, obesity, coronary heart disease and mortality. Nutr Rev 38(9):297-307

Klatsky AL (2010) Alcohol and cardiovascular health. Physiol Behav 100(1):76-81

Klatsky AL, Friedman GD, Armstrong MA, Kipp H (2003) Wine, liquor, beer, and mortality. Am J Epidemiol 158(6):585-595

Kodama S, Tanaka S, Saito K, Shu M, Sone Y, Onitake F, Suzuki E, Shimano H, Yamamoto S, Kondo K, Ohashi Y, Yamada N, Sone H (2007) Effect of aerobic exercise training on serum levels of high-density lipoprotein cholesterol: a meta-analysis. Arch Intern Med 167 (10):999-1008

Kokkinos PF, Holland JC, Narayan P, Colleran JA, Dotson CO, Papademetriou V (1995) Miles run per week and high-density lipoprotein cholesterol levels in healthy, middle-aged men. A doseresponse relationship. Arch Intern Med 155(4):415-420

Kontush A, Chapman MJ (2010) Antiatherogenic function of HDL particle subpopulations: focus on antioxidative activities. Curr Opin Lipidol 21(4):312-318

Koutsari C, Karpe F, Humphreys SM, Frayn KN, Hardman AE (2001) Exercise prevents the accumulation of triglyceride-rich lipoproteins and their remnants seen when changing to a high-carbohydrate diet. Arterioscler Thromb Vasc Biol 21(9):1520-1525

Kralova Lesna I, Suchanek P, Kovar J, Stavek P, Poledne R (2008) Replacement of dietary saturated FAs by PUFAs in diet and reverse cholesterol transport. J Lipid Res 49 (11):2414-2418

Kralova Lesna I, Poledne R, Pagacova L, Stavek P, Pitha J (2012) HDL and apolipoprotein A1 concentrations as markers of cholesterol efflux in middle-aged women: interaction with smoking. Neuro Endocrinol Lett 33(Suppl 2):38-42

Kraus WE, Houmard JA, Duscha BD, Knetzger KJ, Wharton MB, McCartney JS, Bales CW, Henes S, Samsa GP, Otvos JD, Kulkarni KR, Slentz CA (2002) Effects of the amount and intensity of exercise on plasma lipoproteins. N Engl J Med 347(19):1483-1492

Krenz M, Korthuis RJ (2012) Moderate ethanol ingestion and cardiovascular protection: from epidemiologic associations to cellular mechanisms. J Mol Cell Cardiol 52(1):93-104

Labonte ME, Jenkins DJ, Lewis GF, Chiavaroli L, Wong JM, Kendall CW, Hogue JC, Couture P, Lamarche B (2013) Adding MUFA to a dietary portfolio of cholesterol-lowering foods reduces apoAI fractional catabolic rate in subjects with dyslipidaemia. Br J Nutr 110(3):426-436

Lagrost L, Mensink RP, Guyard-Dangremont V, Temme EH, Desrumaux C, Athias A, Hornstra G, Gambert P (1999) Variations in serum cholesteryl ester transfer and phospholipid transfer activities in healthy women and men consuming diets enriched in lauric, palmitic or oleic acids. Atherosclerosis 142(2):395-402

Lichtenstein AH, Appel LJ, Brands M, Carnethon M, Daniels S, Franch HA, Franklin B, KrisEtherton P, Harris WS, Howard B, Karanja N, Lefevre M, Rudel L, Sacks F, Van Horn L, Winston M, Wylie-Rosett J (2006) Diet and lifestyle recommendations revision 2006: a scientific statement from the American Heart Association Nutrition Committee. Circulation 114(1):82-96

Liisanantti MK, Savolainen MJ (2009) Phosphatidylethanol mediates its effects on the vascular endothelial growth factor via HDL receptor in endothelial cells. Alcohol Clin Exp Res 33 (2):283-288 
Lustig RH (2010) Fructose: metabolic, hedonic, and societal parallels with ethanol. J Am Diet Assoc 110(9):1307-1321

Maeda K, Noguchi Y, Fukui T (2003) The effects of cessation from cigarette smoking on the lipid and lipoprotein profiles: a meta-analysis. Prev Med 37(4):283-290

Magnus P, Bakke E, Hoff DA, Hoiseth G, Graff-Iversen S, Knudsen GP, Myhre R, Normann PT, Naess O, Tambs K, Thelle DS, Morland J (2011) Controlling for high-density lipoprotein cholesterol does not affect the magnitude of the relationship between alcohol and coronary heart disease. Circulation 124(21):2296-2302

Makela SM, Jauhiainen M, Ala-Korpela M, Metso J, Lehto TM, Savolainen MJ, Hannuksela ML (2008) HDL2 of heavy alcohol drinkers enhances cholesterol efflux from raw macrophages via phospholipid-rich HDL 2b particles. Alcohol Clin Exp Res 32(6):991-1000

Marmillot P, Munoz J, Patel S, Garige M, Rosse RB, Lakshman MR (2007) Long-term ethanol consumption impairs reverse cholesterol transport function of high-density lipoproteins by depleting high-density lipoprotein sphingomyelin both in rats and in humans. Metabolism 56 (7):947-953

McCall MR, van den Berg JJ, Kuypers FA, Tribble DL, Krauss RM, Knoff LJ, Forte TM (1994) Modification of LCAT activity and HDL structure. New links between cigarette smoke and coronary heart disease risk. Arterioscler Thromb 14(2):248-253

Meissner M, Nijstad N, Kuipers F, Tietge UJ (2010) Voluntary exercise increases cholesterol efflux but not macrophage reverse cholesterol transport in vivo in mice. Nutr Metab (Lond) 7:54

Meissner M, Lombardo E, Havinga R, Tietge UJ, Kuipers F, Groen AK (2011) Voluntary wheel running increases bile acid as well as cholesterol excretion and decreases atherosclerosis in hypercholesterolemic mice. Atherosclerosis 218(2):323-329

Mensink RP, Zock PL, Kester AD, Katan MB (2003) Effects of dietary fatty acids and carbohydrates on the ratio of serum total to HDL cholesterol and on serum lipids and apolipoproteins: a meta-analysis of 60 controlled trials. Am J Clin Nutr 77(5):1146-1155

Micha R, Mozaffarian D (2010) Saturated fat and cardiometabolic risk factors, coronary heart disease, stroke, and diabetes: a fresh look at the evidence. Lipids 45(10):893-905

Miller M, Stone NJ, Ballantyne C, Bittner V, Criqui MH, Ginsberg HN, Goldberg AC, Howard WJ, Jacobson MS, Kris-Etherton PM, Lennie TA, Levi M, Mazzone T, Pennathur S (2011) Triglycerides and cardiovascular disease: a scientific statement from the American Heart Association. Circulation 123(20):2292-2333

Moffatt RJ, Stamford BA, Biggerstaff KD (1995) Influence of worksite environmental tobacco smoke on serum lipoprotein profiles of female nonsmokers. Metabolism 44(12):1536-1539

Moffatt RJ, Biggerstaff KD, Stamford BA (2000) Effects of the transdermal nicotine patch on normalization of HDL-C and its subfractions. Prev Med 31(2 Pt 1):148-152

Moffatt RJ, Chelland SA, Pecott DL, Stamford BA (2004) Acute exposure to environmental tobacco smoke reduces HDL-C and HDL2-C. Prev Med 38(5):637-641

Moriguchi EH, Fusegawa Y, Tamachi H, Goto Y (1991) Effects of smoking on HDL subfractions in myocardial infarction patients: effects on lecithin-cholesterol acyltransferase and hepatic lipase. Clin Chim Acta 195(3):139-143

Mukamal KJ, Conigrave KM, Mittleman MA, Camargo CA Jr, Stampfer MJ, Willett WC, Rimm EB (2003) Roles of drinking pattern and type of alcohol consumed in coronary heart disease in men. N Engl J Med 348(2):109-118

Mulligan JJ, Cluette JE, Kew RR, Stack DJ, Hojnacki JL (1983) Cigarette smoking impairs hepatic uptake of high density lipoproteins. Biochem Biophys Res Commun 112(3):843-850

Naem E, Alcalde R, Gladysz M, Mesliniene S, Jaimungal S, Sheikh-Ali M, Haas MJ, Wong NC, Mooradian AD (2012) Inhibition of apolipoprotein A-I gene by the aryl hydrocarbon receptor: a potential mechanism for smoking-associated hypoalphalipoproteinemia. Life Sci 91 (1-2):64-69

National Diet and Nutrition Survey (2011) Headline results from Years 1 and 2 (combined) of the rolling programme 2008/9-2009/10. http://www.dh.gov.uk/prod_consum_dh/groups/dh_ digitalassets/documents/digitalasset/dh_128550.pdf. 
Neufeld EJ, Mietus-Snyder M, Beiser AS, Baker AL, Newburger JW (1997) Passive cigarette smoking and reduced HDL cholesterol levels in children with high-risk lipid profiles. Circulation 96(5):1403-1407

Nishiwaki M, Ishikawa T, Ito T, Shige H, Tomiyasu K, Nakajima K, Kondo K, Hashimoto H, Saitoh K, Manabe M et al (1994) Effects of alcohol on lipoprotein lipase, hepatic lipase, cholesteryl ester transfer protein, and lecithin:cholesterol acyltransferase in high-density lipoprotein cholesterol elevation. Atherosclerosis 111(1):99-109

Olchawa B, Kingwell BA, Hoang A, Schneider L, Miyazaki O, Nestel P, Sviridov D (2004) Physical fitness and reverse cholesterol transport. Arterioscler Thromb Vasc Biol 24 (6):1087-1091

Pan A, Chen M, Chowdhury R, Wu JH, Sun Q, Campos H, Mozaffarian D, Hu FB (2012) alphaLinolenic acid and risk of cardiovascular disease: a systematic review and meta-analysis. Am J Clin Nutr 96(6):1262-1273

Pattyn N, Cornelissen VA, Eshghi SR, Vanhees L (2013) The effect of exercise on the cardiovascular risk factors constituting the metabolic syndrome: a meta-analysis of controlled trials. Sports Med 43(2):121-133

Phillips NR, Havel RJ, Kane JP (1981) Levels and interrelationships of serum and lipoprotein cholesterol and triglycerides. Association with adiposity and the consumption of ethanol, tobacco, and beverages containing caffeine. Arteriosclerosis 1(1):13-24

Pirillo A, Norata GD, Catapano AL (2013) High-density lipoprotein subfractions-what the clinicians need to know. Cardiology 124(2):116-125

Poobalan A, Aucott L, Smith WC, Avenell A, Jung R, Broom J, Grant AM (2004) Effects of weight loss in overweight/obese individuals and long-term lipid outcomes-a systematic review. Obes Rev 5(1):43-50

Quensel M, Agardh CD, Nilsson-Ehle P (1989a) Nicotine does not affect plasma lipoprotein concentrations in healthy men. Scand J Clin Lab Invest 49(2):149-153

Quensel M, Soderstrom A, Agardh CD, Nilsson-Ehle P (1989b) High density lipoprotein concentrations after cessation of smoking: the importance of alterations in diet. Atherosclerosis 75(2-3):189-193

Rao MN, Liu QH, Marmillot P, Seeff LB, Strader DB, Lakshman MR (2000) High-density lipoproteins from human alcoholics exhibit impaired reverse cholesterol transport function. Metabolism 49(11):1406-1410

Rao MN, Marmillot P, Gong M, Palmer DA, Seeff LB, Strader DB, Lakshman MR (2003) Light, but not heavy alcohol drinking, stimulates paraoxonase by upregulating liver mRNA in rats and humans. Metabolism 52(10):1287-1294

Rashid S, Genest J (2007) Effect of obesity on high-density lipoprotein metabolism. Obesity (Silver Spring) 15(12):2875-2888

Rector RS, Warner SO, Liu Y, Hinton PS, Sun GY, Cox RH, Stump CS, Laughlin MH, Dellsperger KC, Thomas TR (2007) Exercise and diet induced weight loss improves measures of oxidative stress and insulin sensitivity in adults with characteristics of the metabolic syndrome. Am J Physiol Endocrinol Metab 293(2):E500-E506

Richard F, Marecaux N, Dallongeville J, Devienne M, Tiem N, Fruchart JC, Fantino M, Zylberberg G, Amouyel P (1997) Effect of smoking cessation on lipoprotein A-I and lipoprotein A-I:A-II levels. Metabolism 46(6):711-715

Riemens SC, van Tol A, Hoogenberg K, van Gent T, Scheek LM, Sluiter WJ, Dullaart RP (1997) Higher high density lipoprotein cholesterol associated with moderate alcohol consumption is not related to altered plasma lecithin:cholesterol acyltransferase and lipid transfer protein activity levels. Clin Chim Acta 258(1):105-115

Sacks FM, Bray GA, Carey VJ, Smith SR, Ryan DH, Anton SD, McManus K, Champagne CM, Bishop LM, Laranjo N, Leboff MS, Rood JC, de Jonge L, Greenway FL, Loria CM, Obarzanek E, Williamson DA (2009) Comparison of weight-loss diets with different compositions of fat, protein, and carbohydrates. N Engl J Med 360(9):859-873

Sarandol E, Serdar Z, Dirican M, Safak O (2003) Effects of red wine consumption on serum paraoxonase/arylesterase activities and on lipoprotein oxidizability in healthy-men. J Nutr Biochem 14(9):507-512 
Sasahara T, Nestel P, Fidge N, Sviridov D (1998) Cholesterol transport between cells and high density lipoprotein subfractions from obese and lean subjects. J Lipid Res 39(3):544-554

Sattelmair J, Pertman J, Ding EL, Kohl HW 3rd, Haskell W, Lee IM (2011) Dose response between physical activity and risk of coronary heart disease: a meta-analysis. Circulation 124(7):789-795

Schwingshackl L, Hoffmann G (2012) Monounsaturated fatty acids and risk of cardiovascular disease: synopsis of the evidence available from systematic reviews and meta-analyses. Nutrients 4(12):1989-2007

Schwingshackl L, Hoffmann G (2013) Long-term effects of low-fat diets either low or high in protein on cardiovascular and metabolic risk factors: a systematic review and meta-analysis. Nutr J 12:48

Senault C, Mahlberg FH, Renaud G, Girard-Globa A, Chacko GK (1990) Effect of apoprotein cross-linking on the metabolism of human HDL3 in rat. Biochim Biophys Acta 1046(1):81-88

Seres I, Bajnok L, Harangi M, Sztanek F, Koncsos P, Paragh G (2010) Alteration of PON1 activity in adult and childhood obesity and its relation to adipokine levels. Adv Exp Med Biol 660:129-142

Shennan NM, Seed M, Wynn V (1985) Variation in serum lipid and lipoprotein levels associated with changes in smoking behaviour in non-obese Caucasian males. Atherosclerosis 58 $(1-3): 17-25$

Sierksma A, van der Gaag MS, van Tol A, James RW, Hendriks HF (2002) Kinetics of HDL cholesterol and paraoxonase activity in moderate alcohol consumers. Alcohol Clin Exp Res 26 (9):1430-1435

Sierksma A, Vermunt SH, Lankhuizen IM, van der Gaag MS, Scheek LM, Grobbee DE, van Tol A, Hendriks HF (2004) Effect of moderate alcohol consumption on parameters of reverse cholesterol transport in postmenopausal women. Alcohol Clin Exp Res 28(4):662-666

Sigal RJ, Kenny GP, Boule NG, Wells GA, Prud'homme D, Fortier M, Reid RD, Tulloch H, Coyle D, Phillips P, Jennings A, Jaffey J (2007) Effects of aerobic training, resistance training, or both on glycemic control in type 2 diabetes: a randomized trial. Ann Intern Med 147 (6):357-369

Singh IM, Shishehbor MH, Ansell BJ (2007) High-density lipoprotein as a therapeutic target: a systematic review. JAMA 298(7):786-798

Stanhope KL, Schwarz JM, Keim NL, Griffen SC, Bremer AA, Graham JL, Hatcher B, Cox CL, Dyachenko A, Zhang W, McGahan JP, Seibert A, Krauss RM, Chiu S, Schaefer EJ, Ai M, Otokozawa S, Nakajima K, Nakano T, Beysen C, Hellerstein MK, Berglund L, Havel PJ (2009) Consuming fructose-sweetened, not glucose-sweetened, beverages increases visceral adiposity and lipids and decreases insulin sensitivity in overweight/obese humans. J Clin Invest 119 (5):1322-1334

Stanhope KL, Schwarz JM, Havel PJ (2013) Adverse metabolic effects of dietary fructose: results from the recent epidemiological, clinical, and mechanistic studies. Curr Opin Lipidol 24 (3): 198-206

Stubbe I, Eskilsson J, Nilsson-Ehle P (1982) High-density lipoprotein concentrations increase after stopping smoking. BMJ 284(6328):1511-1513

Tall AR (2002) Exercise to reduce cardiovascular risk - how much is enough? N Engl J Med 347 (19):1522-1524

Tambalis K, Panagiotakos DB, Kavouras SA, Sidossis LS (2009) Responses of blood lipids to aerobic, resistance, and combined aerobic with resistance exercise training: a systematic review of current evidence. Angiology 60(5):614-632

Tchernof A, Despres JP (2013) Pathophysiology of human visceral obesity: an update. Physiol Rev 93(1):359-404

Tian L, Jia L, Mingde F, Tian Y, Xu Y, Tian H, Yang Y (2006) Alterations of high density lipoprotein subclasses in obese subjects. Lipids 41(8):789-796

Tian L, Xu Y, Fu M, Peng T, Liu Y, Long S (2011) The impact of plasma triglyceride and apolipoproteins concentrations on high-density lipoprotein subclasses distribution. Lipids Health Dis 10:17 
Tselepis AD, Panagiotakos DB, Pitsavos C, Tellis CC, Chrysohoou C, Stefanadis C (2009) Smoking induces lipoprotein-associated phospholipase A2 in cardiovascular disease free adults: the ATTICA Study. Atherosclerosis 206(1):303-308

Tuomilehto J, Tanskanen A, Salonen JT, Nissinen A, Koskela K (1986) Effects of smoking and stopping smoking on serum high-density lipoprotein cholesterol levels in a representative population sample. Prev Med 15(1):35-45

Ueyama K, Yokode M, Arai H, Nagano Y, Li ZX, Cho M, Kita T (1998) Cholesterol efflux effect of high density lipoprotein is impaired by whole cigarette smoke extracts through lipid peroxidation. Free Radic Biol Med 24(1):182-190

Uusitupa M, Peltonen M, Lindstrom J, Aunola S, Ilanne-Parikka P, Keinanen-Kiukaanniemi S, Valle TT, Eriksson JG, Tuomilehto J (2009) Ten-year mortality and cardiovascular morbidity in the Finnish Diabetes Prevention Study - secondary analysis of the randomized trial. PLoS ONE 4(5):e5656

Uzun H, Zengin K, Taskin M, Aydin S, Simsek G, Dariyerli N (2004) Changes in leptin, plasminogen activator factor and oxidative stress in morbidly obese patients following open and laparoscopic Swedish adjustable gastric banding. Obes Surg 14(5):659-665

van der Gaag MS, van Tol A, Scheek LM, James RW, Urgert R, Schaafsma G, Hendriks HF (1999) Daily moderate alcohol consumption increases serum paraoxonase activity; a diet-controlled, randomised intervention study in middle-aged men. Atherosclerosis 147(2):405-410

Vazquez E, Sethi AA, Freeman L, Zalos G, Chaudhry H, Haser E, Aicher BO, Aponte A, Gucek M, Kato GJ, Waclawiw MA, Remaley AT, Cannon RO 3rd (2012) High-density lipoprotein cholesterol efflux, nitration of apolipoprotein A-I, and endothelial function in obese women. Am J Cardiol 109(4):527-532

Verdugo RA, Zeller T, Rotival M, Wild PS, Munzel T, Lackner KJ, Weidmann H, Ninio E, Tregouet DA, Cambien F, Blankenberg S, Tiret L (2013) Graphical modeling of gene expression in monocytes suggests molecular mechanisms explaining increased atherosclerosis in smokers. PLoS ONE 8(1):e50888

Vest AR, Heneghan HM, Agarwal S, Schauer PR, Young JB (2012) Bariatric surgery and cardiovascular outcomes: a systematic review. Heart 98(24):1763-1777

Wang H, Peng DQ (2011) New insights into the mechanism of low high-density lipoprotein cholesterol in obesity. Lipids Health Dis 10:176

Wen CP, Wai JP, Tsai MK, Yang YC, Cheng TY, Lee MC, Chan HT, Tsao CK, Tsai SP, Wu X (2011) Minimum amount of physical activity for reduced mortality and extended life expectancy: a prospective cohort study. Lancet 378(9798):1244-1253

Wilson PW, Garrison RJ, Abbott RD, Castelli WP (1983) Factors associated with lipoprotein cholesterol levels. The Framingham study. Arteriosclerosis 3(3):273-281

Wing RR (2010) Long-term effects of a lifestyle intervention on weight and cardiovascular risk factors in individuals with type 2 diabetes mellitus: four-year results of the Look AHEAD trial. Arch Intern Med 170(17):1566-1575

Wing RR, Bolin P, Brancati FL, Bray GA, Clark JM, Coday M, Crow RS, Curtis JM, Egan CM, Espeland MA, Evans M, Foreyt JP, Ghazarian S, Gregg EW, Harrison B, Hazuda HP, Hill JO, Horton ES, Hubbard VS, Jakicic JM, Jeffery RW, Johnson KC, Kahn SE, Kitabchi AE, Knowler WC, Lewis CE, Maschak-Carey BJ, Montez MG, Murillo A, Nathan DM, Patricio J, Peters A, Pi-Sunyer X, Pownall H, Reboussin D, Regensteiner JG, Rickman AD, Ryan DH, Safford M, Wadden TA, Wagenknecht LE, West DS, Williamson DF, Yanovski SZ (2013) Cardiovascular effects of intensive lifestyle intervention in type 2 diabetes. N Engl J Med 369(2):145-154

Woldt E, Sebti Y, Solt LA, Duhem C, Lancel S, Eeckhoute J, Hesselink MK, Paquet C, Delhaye S, Shin Y, Kamenecka TM, Schaart G, Lefebvre P, Neviere R, Burris TP, Schrauwen P, Staels B, Duez H (2013) Rev-erb-alpha modulates skeletal muscle oxidative capacity by regulating mitochondrial biogenesis and autophagy. Nat Med 19(8):1039-1046

Yudkin J (1972) Sugar and disease. Nature 239(5369):197-199

Zhang YH, An T, Zhang RC, Zhou Q, Huang Y, Zhang J (2013) Very high fructose intake increases serum LDL-cholesterol and total cholesterol: a meta-analysis of controlled feeding trials. J Nutr 143(9):1391-1398 